\title{
Unusual Maternal Uniparental Isodisomic X Chromosome Mosaicism with Asymmetric $Y$ Chromosomal Rearrangement
}

\author{
B.Y. Lee ${ }^{a, d}$ S.Y. Kim ${ }^{a}$ J.Y.Park ${ }^{a}$ E.Y.Choi ${ }^{a}$ D.J. Kim ${ }^{a} \quad$ J.W. Kim ${ }^{a}$ H.M. Ryu ${ }^{\text {a b }}$ \\ Y.H. Cho ${ }^{d}$ S.Y.Park ${ }^{\text {a }}$ J.T. Seo ${ }^{c}$ \\ ${ }^{a}$ Laboratory of Medical Genetics, ${ }^{b}$ Department of Obstetrics and Gynecology and ${ }^{c}$ Department of Urology, \\ Cheil General Hospital and Women's Healthcare Center, Kwandong University College of Medicine, and \\ ${ }^{\mathrm{d}}$ Department of Medical Genetics, College of Medicine, Hanyang University, Seoul, Korea
}

\section{Key Words}

Azoospermia - Chromosome rearrangement - Isodisomy .

Mosaicism $\cdot Y$ chromosome

\begin{abstract}
Infertile men with azoospermia commonly have associated microdeletions in the azoospermia factor (AZF) region of the $Y$ chromosome, sex chromosome mosaicism, or sex chromosome rearrangements. In this study, we describe an unusual $46, X X$ and $45, X$ mosaicism with a rare $Y$ chromosome rearrangement in a phenotypically normal male patient. The patient's karyotype was $46, \mathrm{XX}[50] / 45, \mathrm{X}[25] / 46, \mathrm{X}, \operatorname{der}(\mathrm{Y})$ (pter $\rightarrow$ q11.222:: p11.2 $\rightarrow$ pter)[25]. The derivative $Y$ chromosome had a deletion at Yq11.222 and was duplicated at Yp11.2. Two copies of the SRY gene were confirmed by fluorescence in situ hybridization analysis, and complete deletion of the AZFb and AZFc regions was shown by multiplex$P C R$ for microdeletion analysis. Both $X$ chromosomes of the predominant mosaic cell line $(46, \mathrm{XX})$ were isodisomic and derived from the maternal gamete, as determined by examination of short tandem repeat markers. We postulate that the derivative $Y$ chromosome might have been generated during paternal meiosis or early embryogenesis. Also, we suggest that the very rare mosaicism of isodisomic $X$ chro-
\end{abstract}

mosomes might be formed during maternal meiosis II or during postzygotic division derived from the $46, X, \operatorname{der}(Y) /$ $45, X$ lineage because of the instability of the derivative $Y$ chromosome. To our knowledge, this is the first confirmatory study to verify the origin of a sex chromosome mosaicism with a $Y$ chromosome rearrangement.

(c) 2014 S. Karger AG, Basel

Among the genetic causes of male infertility, chromosomal abnormalities have been reported in approximately $6 \%$ of cases [Foresta et al., 2001], and Y chromosome microdeletions account for spermatogenic failure in 5-20\% of men with azoospermia [Vollrath et al., 1992; Vogt et al., 1996; Vogt, 1998, 2004]. Structural abnormalities of the Y chromosome have been observed in 10-20\% of men with non-obstructive azoospermic infertility [Peschka et al., 1999]. The most common structural Y chromosome aberration in infertile men with azoospermia has been reported to be an isodicentric or isochromosome $\mathrm{Y}$, with duplications in the Yp region and deletions in the Yq region or vice versa [Tuck-Muller et al., 1995; Siffroi et al., 2000]. These Y chromosome anomalies are frequently observed with sex chromosome mosaicism such as $45, \mathrm{X}, 47, \mathrm{XXY}$, and/or $46, \mathrm{XY}$. It is generally

\section{KARGER}

E-Mail karger@karger.com

www.karger.com/cgr (c) 2014 S. Karger AG, Base

$1424-8581 / 14 / 1422-0079 \$ 39.50 / 0$
Ju Tae Seo

Department of Urology, Cheil General Hospital and Women's Healthcare Center Kwandong University College of Medicine

1-19, Mukjeong-dong, Jung-gu, Seoul 100-380 (Korea)

E-Mail byl44@hanmail.net 
thought that mosaicism might occur during meiosis for abnormal X-Y bivalents or as a result of a postzygotic mitotic error due to structural instability of the Y chromosome during cell division [Antonelli et al., 2011]. Consequently, clinically different phenotypes have been observed such as Turner syndrome, Klinefelter syndrome, ambiguous genitalia, sex reversal, mixed gonadal dysgenesis, spermatogenic failure, and a normal male or female phenotype. It has been proposed that the phenotype of patients with these sex chromosome abnormalities can be predicted according to the breakpoints of the chromosomal rearrangement and the predominant cell line of the sex chromosome mosaicism [Hsu, 1994].

The most frequent clinically observed mosaicism of sex chromosome aneuploidy is a combination of 45,X, $47, \mathrm{XXX}$, or $47, \mathrm{XXY}$ with a normal $46, \mathrm{XX}$ or $46, \mathrm{XY}$ cell lineage [Oliveira et al., 2009]. The sex phenotype and sexual development of patients with sex chromosome mosaicism depends on the presence of the Y chromosome [Hsu and Perlis, 1984; Wheeler et al., 1988; Mancini et al., 2008; Oliveira et al., 2009; Shinawi et al., 2010]. In particular, a 46,XX/46,XY sex chromosome mosaicism or chimerism has rarely been reported [Malan et al., 2006; Winberg et al., 2010; Yamazawa et al., 2010].

We describe a complex sex chromosome mosaicism including an isodisomic 46, XX predominant lineage in a normal phenotypic male carrying an aberrated Y chromosome with a rare asymmetric duplication-deletion. We attempted to verify the complex sex chromosome mosaicism and suggest hypotheses to explain the occurrence of the derivative $\mathrm{Y}$ chromosome and the generation of a mosaic cell line.

\section{Materials and Methods}

\section{Clinical Findings}

A 35-year-old male patient with normal phenotype and intelligence was referred for cytogenetic analysis because of infertility. His karyotype indicated a 46,XX[15]/45,X[3]/46,XY[12] chromosomal mosaicism. His height was $176 \mathrm{~cm}$ and his weight was $76 \mathrm{~kg}$ (body mass index: 24.5). Semen analysis was performed according to WHO guidelines (http://www.who.int/reproductivehealth/topics/infertility/cooper_et_al_hru.pdf) and revealed azoospermia. Hormonal evaluation revealed high levels of follicle-stimulating hormone (FSH $31.7 \mathrm{mIU} / \mathrm{ml}$, normal reference: $1.5-12.4 \mathrm{mIU} / \mathrm{ml}$ ) and luteinizing hormone ( $\mathrm{LH} 13.9 \mathrm{mIU} / \mathrm{ml}$, normal reference: $1.7-$ $8.6 \mathrm{mIU} / \mathrm{ml}$ ), whereas serum testosterone and estradiol levels were within the normal ranges $(4.0 \mathrm{ng} / \mathrm{ml}$, normal reference: $2.41-8.27$ $\mathrm{ng} / \mathrm{ml} ; 40.2 \mathrm{pg} / \mathrm{ml}$, normal reference: $7.4-42.6 \mathrm{pg} / \mathrm{ml}$, respectively). An andrological examination revealed that testicular volumes on both sides were reduced to $10 \mathrm{ml}$ and $12 \mathrm{ml}$ for the left and right testis, respectively (normal reference: $>15 \mathrm{ml}$ ).
Cytogenetic Analysis

We performed conventional cytogenetic analyses according to standard techniques. High-resolution chromosomes of 700-band levels were prepared from cultured blood cells, and 100 metaphases of the patient and 20 metaphases of the patient's parents were analyzed. C-banding and Da/DAPI staining confirmed the location of the centromere and the heterochromatic region of the $\mathrm{Y}$ chromosome. Fluorescence in situ hybridization (FISH) analyses were carried out on 20 metaphases with the following Y chromosome-specific probes: CEP Y Sat III Spectrum Green/CEP Y Alpha Spectrum Orange (Vysis Inc., Downers Grove, Ill., USA) and LSI SRY Spectrum Orange/CEP X Spectrum Green (Vysis Inc.).

\section{Allelic Analysis of X Chromosomes}

Genomic DNA was extracted from peripheral blood of the patient and the patient's parents (QIAmp Mini DNA Kit, QIAGEN $\mathrm{GmbH}$, Hilden, Germany), and allelic analysis was performed using Aneufast ${ }^{\mathrm{TM}}$ QF-PCR Kit (Molgentix SL, Barcelona, Spain). Amplified products of 18 sex chromosome loci (SRY, DXYS218, AMXY, DXS6807, DXS8378, DXS9902, DXS7132, SBMA, DXS6803, DXS9898, DXS6809, DXS6789, DXS7424, GATA172D05, HPRT, DXS8377, DXS7423, X22) and 12 loci (D13S305, D13S634, D13S258, D13S631，D18S391，D18S535, D18S386, D18S390, D21S1414, D21S1435, D21S1411, D21S1446) on chromosomes 13,18 , and 21 with short tandem repeat (STR) markers were analyzed by capillary electrophoresis using an ABI 3130 XL Genetic Analyzer and Gene Mapper Software version 4.0 (Applied Biosystems, Foster City, Calif., USA).

\section{Microdeletion Analysis of the Y Chromosome}

Four rounds of multiplex-PCR were carried out on the patient's DNA together with a normal male positive control and normal female negative control. Information on oligonucleotides used for multiplex-PCR analysis is summarized in table 1. PCR was performed using a GeneAmp PCR System 2700 Thermal Cycler (Applied Biosystems) with the following cycle conditions: initial denaturation at $95^{\circ} \mathrm{C}$ for $10 \mathrm{~min}$, followed by 35 cycles at $95^{\circ} \mathrm{C}$ for 10 min, $62^{\circ} \mathrm{C}$ for $90 \mathrm{~s}$, and $65^{\circ} \mathrm{C}$ for $90 \mathrm{~s}$, with a final extension at $65^{\circ} \mathrm{C}$ for $10 \mathrm{~min}$. Amplified products were separated by $3 \%$ Nusieve agarose gel electrophoresis and visualized under ultraviolet illumination.

\section{Array-Based Comparative Genomic Hybridization (aCGH)} Analysis

To investigate duplicated and deleted regions of the rearranged derivative $\mathrm{Y}$ chromosome, we performed aCGH using an Agilent 44k oligo-array (Agilent Technologies, Santa Clara, Calif., USA) according to the manufacturer's instructions. Microarray image files were quantified using Agilent Genomic Workbench Lite Edition 6.0 (Agilent Technologies).

\section{Results}

\section{Cytogenetic Analysis}

The conventional GTL-banded karyotype of cultured blood cells from the patient was 46,XX[50]/45,X[25]/ 46,X,der(Y)(pter $\rightarrow$ q11.23::p11.2 $\rightarrow$ pter)[25] (fig. 1A).
Lee/Kim/Park/Choi/Kim/Kim/Ryu/ Cho/Park/Seo 
Table 1. Summary of information on the sequence-tagged site (STS) markers and primers for the analysis of microdeletion of the azoospermia factor $(\mathrm{AZF})$ regions

\begin{tabular}{|c|c|c|c|c|c|c|c|}
\hline STS & Locus & GenBank & Primer $\left(5^{\prime}-3^{\prime}\right)$ & Size, bp & Chromosome & AZF region & Result \\
\hline sY14 & $S R Y$ & G38356 & $\begin{array}{l}\text { F: gaatattcccgctctccgg } \\
\text { R: gctggtgctccattcttgag }\end{array}$ & 470 & Yp11.3 & - & ++ \\
\hline sY86 & DYS148 & G49207 & $\begin{array}{l}\text { F: gtgacacacagactatgcttc } \\
\text { R: acacacagagggacaaccc }\end{array}$ & 318 & Yq11.21 & a & + \\
\hline sY84 & DYS273 & G12019 & $\begin{array}{l}\text { F: agaagggtctgaaagcagg } \\
\text { R: gcctactacctggaggcttc }\end{array}$ & 326 & Yq11.21 & a & + \\
\hline sY124 & DYS215 & G40975 & $\begin{array}{l}\text { F: caggcaggacagcttaaaag } \\
\text { R: actgtggcaaagttgctttc }\end{array}$ & 109 & Yq11.222 & $\mathrm{b}$ & - \\
\hline sY127 & DYS218 & G11998 & $\begin{array}{l}\text { F: ctaggctcacaaacgaaaag } \\
\text { R: ctgcaggcagtaataaggg }\end{array}$ & 277 & Yq11.222 & $\mathrm{b}$ & - \\
\hline sY134 & DYS224 & G12001 & $\begin{array}{l}\text { F: gcttaaaatgtttgagaagcc } \\
\text { R: catcatgctatgcacttcag }\end{array}$ & 249 & Yq11.223 & $\mathrm{b}$ & - \\
\hline sY147 & DYF83S1 & G40976 & $\begin{array}{l}\text { F: tttctcgtttgatgatcctag } \\
\text { R: ttaatatgagaatgagaacagatg }\end{array}$ & 100 & Yq11.223 & c & - \\
\hline sY242 & DAZ & G65824 & $\begin{array}{l}\text { F: acacagtagcagcgggagttac } \\
\text { R: tctgccactaaactgtaagctcc }\end{array}$ & 233 & Yq11.223 & c & - \\
\hline sY254 & DAZ & G38349 & $\begin{array}{l}\text { F: gggtgttaccagaaggcaaaatc } \\
\text { R: gaaccgtatctaccaaagcagc }\end{array}$ & 380 & Yq11.223 & c & - \\
\hline sY255 & DAZ & G65827 & $\begin{array}{l}\text { F: gttacaggattcggcgtg } \\
\text { R: ctcgtcatgtgcagccac }\end{array}$ & 123 & Yq11.223 & c & - \\
\hline sY158 & ZFX & NW_001842360 & $\begin{array}{l}\text { F: ccattcacacgaaagactatcc } \\
\text { R: agacctgactgtaaaatctccc }\end{array}$ & 585 & Xp21.3 & - & + \\
\hline
\end{tabular}

The derivative $\mathrm{Y}$ chromosome was monocentric without the Yq12 heterochromatin region as determined by CBGbanding, Da/DAPI stain, and FISH techniques (fig. 1B$D)$. In addition, the $S R Y$ gene-specific FISH probe revealed fluorescence signals at both ends of the derivative $Y$ chromosome, indicating a duplication of the $S R Y$ gene (fig. 1E). There were no translocated signals between the $\mathrm{X}$ and the derivative $\mathrm{Y}$ chromosomes in the $46, \mathrm{XX}$ cell line (data not shown). The parental karyotypes were both normal.

\section{Allelic Analysis of X Chromosomes}

An allelic analysis using STR markers to clarify the origin of the mosaic 46,XX cell lineage in the patient's karyotype showed that it was composed of maternally derived isodisomic X chromosomes. Among 18 loci analyzed for 


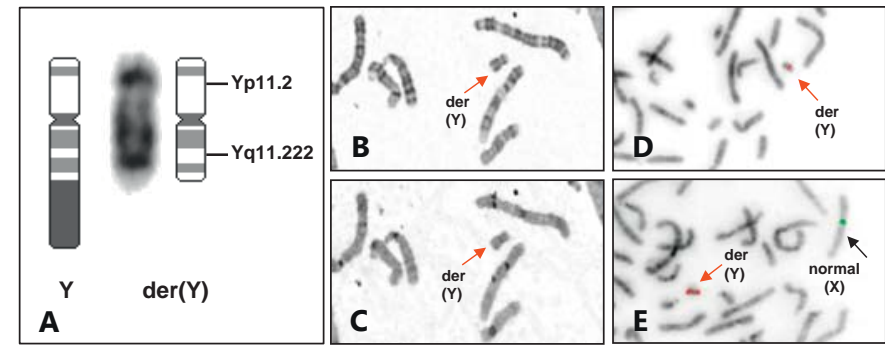

Fig. 1. Cytogenetic partial karyotype, C-banding, and FISH analyses. A Normal Y chromosome ideogram (left), patient's GTLbanded derivative $\mathrm{Y}$ chromosome (middle), and rearranged ideogram (right), showing a duplicated Yp11.2 region and a deletion below the Yq11.222 region. G-banding (B) and C-banding (C) show the location of the centromere of the derivative $\mathrm{Y}$ chromosome $(\operatorname{der}(\mathrm{Y}))$ and a deficiency of Yq heterochromatin. D FISH analysis shows that $\operatorname{der}(\mathrm{Y})$ has a monocentromere with red signals and a deleted Yq12 region with no green signal (CEP Y Alpha Spectrum Orange/CEP Y Sat III Spectrum Green). E The derivative Y chromosome showed duplicated $S R Y$ fluorescence red signals (red arrow, LSI SRY Spectrum Orange/CEP X Spectrum Green).

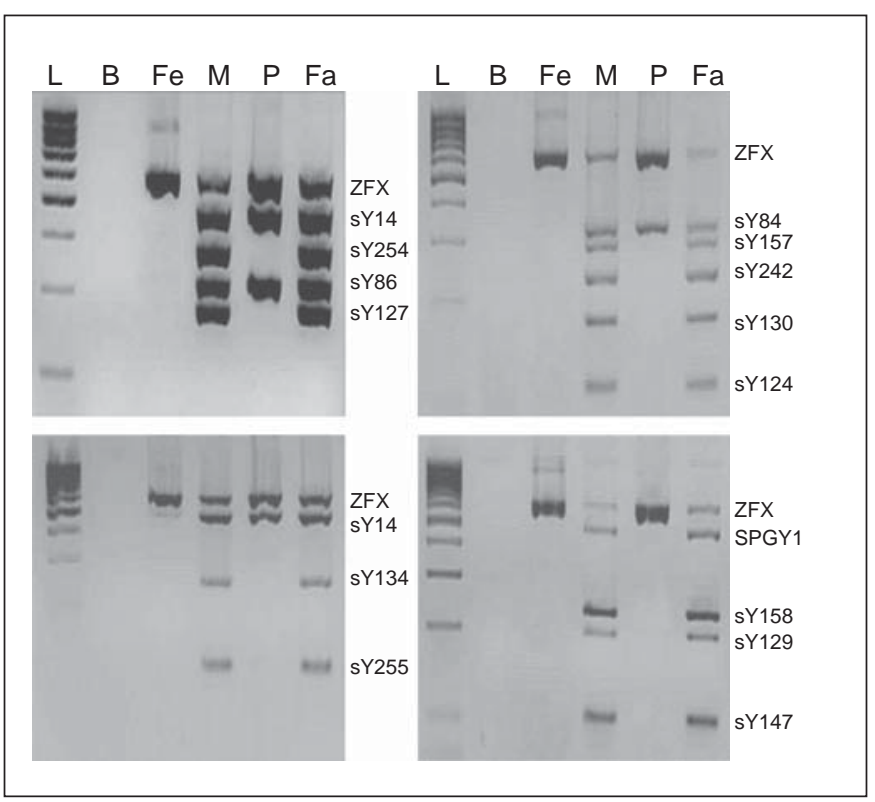

Fig. 2. Multiplex-PCR analysis with STR markers for microdeletion of the azoospermia factor (AZF) region. Patient's sample shows complete deletion of the AZFb and AZFc regions. The specimen of the patient's father presents no microdeletion for any of the tested sites. For the location of the different STS markers, see table 1. L: DNA ladder; B: blank; Fe: female negative control; M: male positive control; P: patient; Fa: patient's father; ZFX: zinc finger X chromosomal protein.

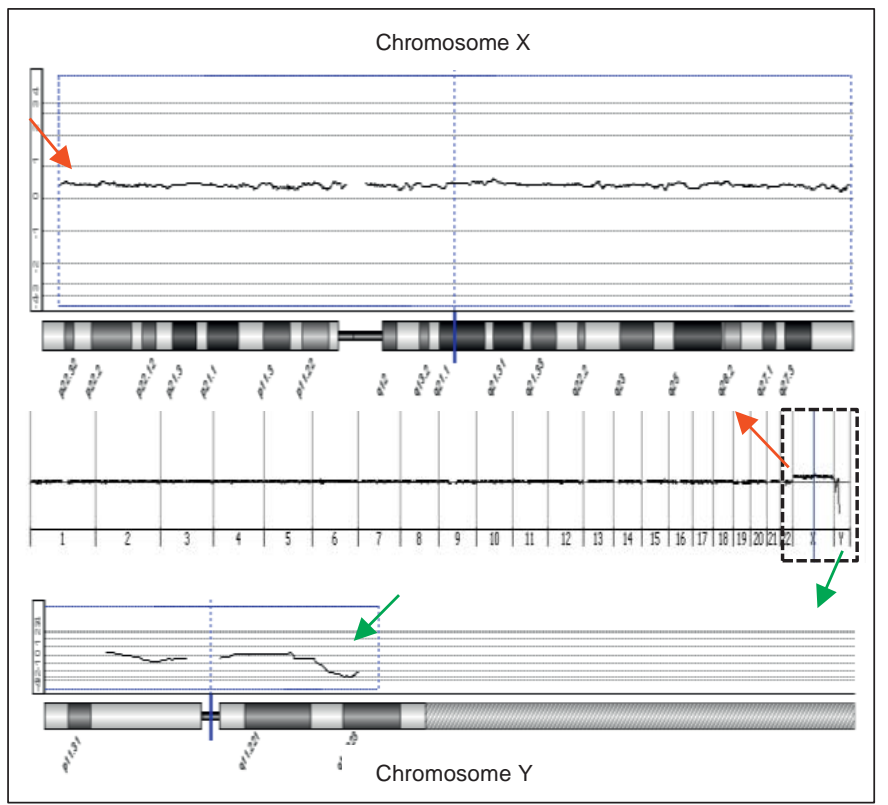

Fig. 3. The profile of aCGH for the patient shows average combined data and elevated signal $\log 2$ ratio $(0-1.0)$ on the $\mathrm{Y}$ axis for the $\mathrm{X}$ chromosome because of the high proportion of the 46,XX cell line (50\%) (upper and middle panel, red arrows). The profile for the derivative $\mathrm{Y}$ chromosome shows a deleted signal, displayed as $<0$ in the $\log 2$ ratio plot, below the Yq11.222 region and approximately $41.95 \mathrm{Mb}$ in size (middle and lower panel, green arrows).

sex chromosome markers (SRY, DXYS218, AMXY, DXS6807, DXS8378, DXS9902, DXS7132, SBMA, DXS6803, DXS9898, DXS6809, DXS6789, DXS7424, GATA172D05, HPRT, DXS8377, DXS7423, X22), all of the patient's X-chromosome-related alleles were monoalleles concordant with maternal alleles. In particular, 4 STR markers (DXS6789, GATA172D05, HPRT, and DXS8377) showed isodisomic alleles that were clearly maternal in origin. For autosomes 13, 18, and 21, all 12 markers were determined to be either monoallelic for either parental allele or bi-allelic with contribution from the parents (table 2).

\section{Microdeletion Analysis of the Y Chromosome}

Of 15 STS markers on the Y chromosome, amplification products of 12 STS loci were not detected in the $\mathrm{AZFb}$ to AZFc regions, indicating a complete deletion from Yq11.222 to Yq11.223 (fig. 2). The STS loci for the $S R Y$ gene (sY14) and the AZFa region (sY86 and sY84) were detected. Combined analysis of the results of cytogenetic, molecular cytogenetic, and location analyses of the deleted STS loci indicated a karyotype of 46,XX[50]/ 45,X[25]/46,X,der(Y)(pter $\rightarrow$ q11.222::p11.2 $\rightarrow$ pter $)[25]$. 
Table 2. Comparison of allele in size (base pair) between patient and parents examined by QF-PCR products of microsatellite markers on chromosomes $13,18,21, \mathrm{X}$, and $\mathrm{Y}$

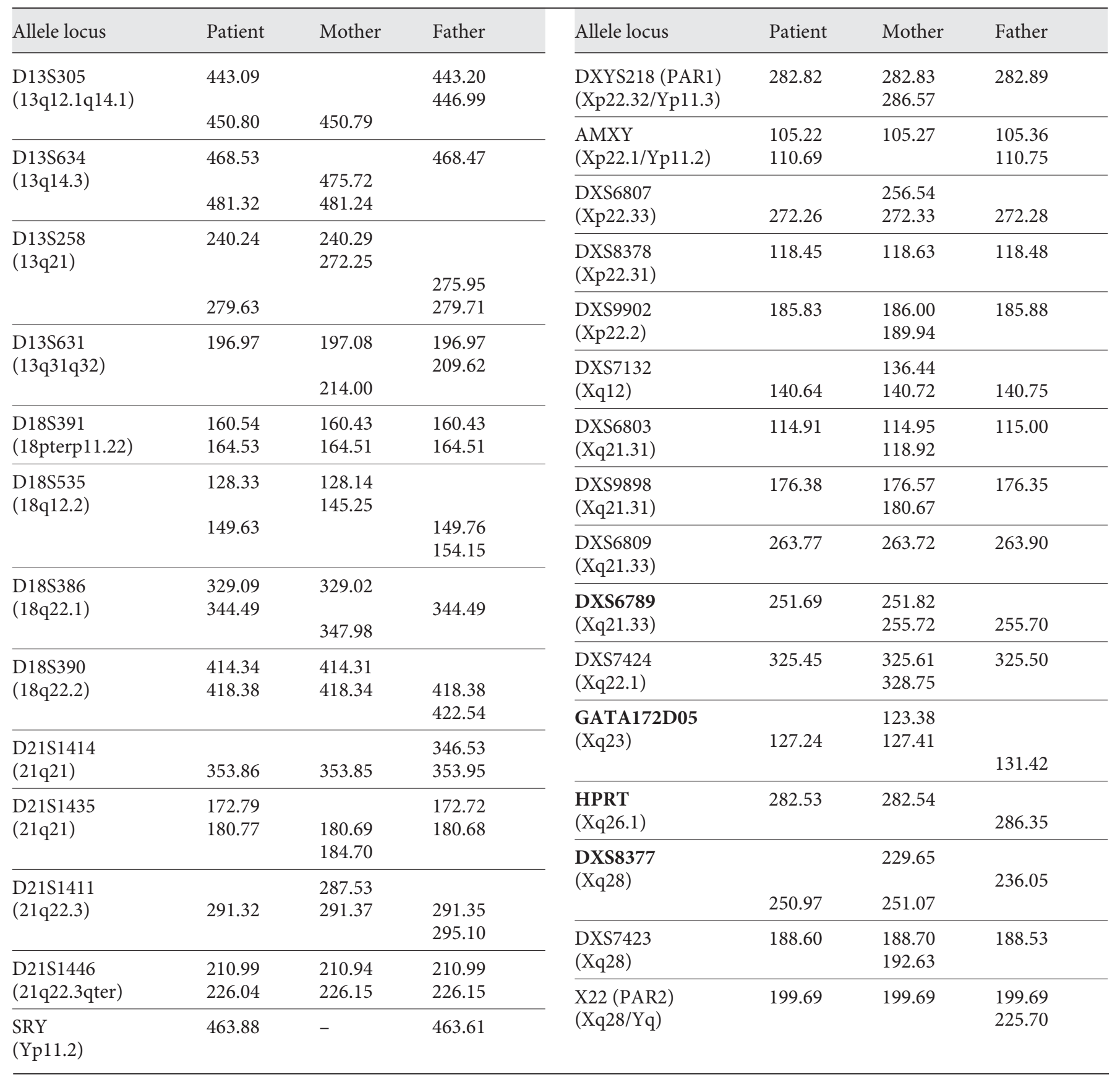

STR markers in bold show isodisomic alleles that are clearly maternal in origin. 


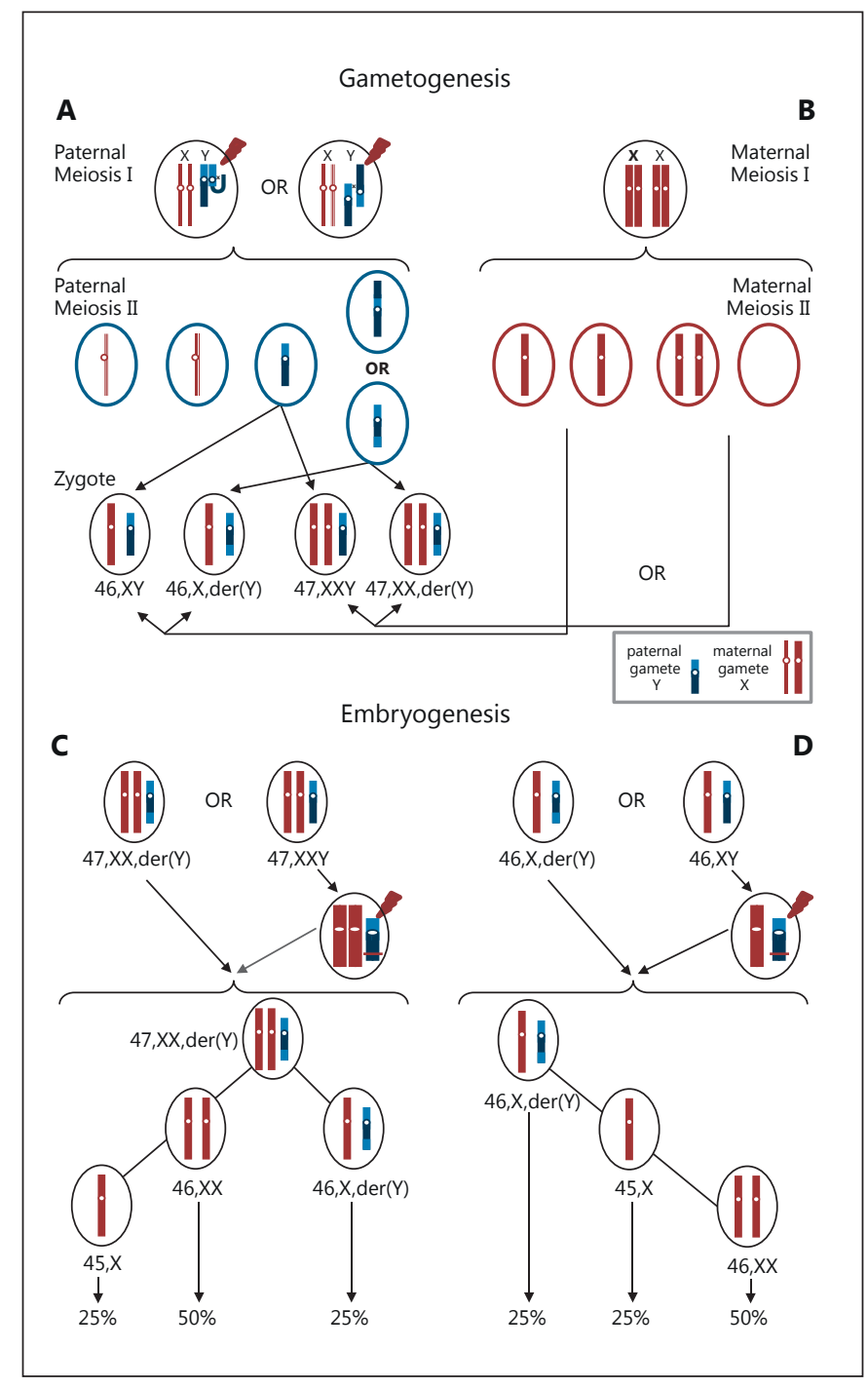

Fig. 4. Schematic representation of the generation of the derivative $\mathrm{Y}$ chromosome and formation of a mosaic cell lineage. For the paternal gamete, the derivative $\mathrm{Y}$ chromosome could be generated via the synapsis for homologous recombination between sister chromatids or by intrachromatid recombination during prophase of paternal meiosis I. Unequal chromatid exchanges may result in the paternal gamete presenting segmental duplication of Yp and deletion of $\mathrm{Yq}(\mathbf{A})$. Alternatively, inappropriate recombination could occur in a normal zygote during postzygotic mitosis in very early embryonic development (C, D). For maternal gametes, nondisjunction in maternal meiosis may result in gametes with $23, \mathrm{X}$ or 24,XX disomy, and 46,XX and 45, X lineages could arise from a 47,XXY zygote during postzygotic cell division (B, C). Another possible mechanism is derivation of the $45, \mathrm{X}$ and $46, \mathrm{XX}$ lineage from a 46,X,der(Y) zygote after fertilization (D).

\section{aCGH Analysis}

aCGH data indicated a relative increase of $\mathrm{X}$ chromosome proportion resulting from 46,XX cell line mosaicism and partial loss of $Y$ chromosome material (fig. 3). The rearranged $\mathrm{Y}$ chromosome was duplicated from the Yp terminal to Yp11.2 (approximately $5.65 \mathrm{Mb}$ ) and deleted from Yq11.222 to the Yq terminal (approximately $41.95 \mathrm{Mb})$.

\section{Discussion}

The patient showed a normal male phenotype, and no complex diseases were detected except for azoospermia. However, the de novo complex chromosomal rearrangement of the derivative $\mathrm{Y}$ chromosome included a duplicated partial Yp region containing 2 copies of the $S R Y$ gene and the deletion of the entire $\mathrm{AZFb}$ and $\mathrm{AZFC}$ regions. Moreover, the cell lineages 46,XX, 45,X, and 46,X,der(Y) formed a complex sex chromosome mosaicism.

To date, 3 similar cases [Roovere et al., 2007; Cui et al., 2009; Shi et al., 2011] have been reported in which a non-mosaic rearranged Y chromosome was duplicated in the Yp region at the end of a partial deletion of Yq. Roovere et al. [2007] reported a normal phenotypic azoospermic male with the karyotype $46, \mathrm{X}, \operatorname{der}(\mathrm{Y})(\mathrm{pter} \rightarrow \mathrm{q} 11.2::$ p11.3 $\rightarrow$ pter) who showed clinical characteristics similar to our case. A female case, 46,X,der $(Y)$ (pter $\rightarrow$ q11.23:: pter $\rightarrow$ p11.31 or p11.2:), exhibited short stature and agonadism [Cui et al., 2009]. Recently, an infertile man with a normal 46,XY karyotype was found to have a partial AZFb deletion and Yp11.2 duplication with severe oligoasthenoteratozoospermia [Shi et al., 2011].

The most common abnormality of the $\mathrm{Y}$ chromosome is a symmetric isodicentric or isochromosome $\mathrm{Y}$, consisting of duplicated and deleted regions [Bertini et al., 2005; Lin et al., 2005]. Recently, the mechanisms of isodicentric and isochromosome $\mathrm{Y}$ have been proposed to involve activation of intra- and interchromatid crossover and noncrossover pathways by massive palindrome-borne mirror-image gene pairs [Lange et al., 2009]. Because of the instability of these iso/isodicentric Y chromosomal abnormalities, a similarly rearranged structure would probably accompany additional mosaic cell lines such as 45 , $\mathrm{X}$ or 47,XXY [Tuck-Muller et al., 1995; Siffroi et al., 2000]. In this case, during the prophase stage of paternal meiosis I, synapsis and recombination may occur due to the palindromic repetitive sequences between sister chromatids or within chromatids of the derivative $\mathrm{Y}$ chromosome [Lange et al., 2009]. Unequal chromatid exchanges may 
result in a paternal gamete with segmental duplication of the $\mathrm{Yp}$ region and deletions in $\mathrm{Yq}$, including the complete $\mathrm{AZFb}$ and AZFc regions (fig. 4A). Another possible mechanism is inappropriate somatic recombination in postzygotic mitosis during early embryonic development [Patsalis et al., 2005] after which the derivative $Y$ chromosome cannot form the X-Y bivalent, resulting in failure to initiate spermatogenesis [Antonelli et al., 2011] (fig. 4C, D).

The present unusual mosaicism, 46,XX[50]/45,X[25]/ $46, \mathrm{X}, \operatorname{der}(\mathrm{Y})[25]$, includes an isodisomic X chromosome in the 46,XX lineage. In general, uniparental disomy (UPD) may result from trisomy rescue, monosomy duplication, or gamete complementation [Engel, 2006].

At first, we hypothesized that the 46,XX cell lineage might have been formed from a distinct zygote, similar to chimerism in a hermaphrodite. There are a few reports of true hermaphroditism with 46,XX/46,XY karyotypes which have shown a great degree of phenotypic variation, ranging from normal male or female to ambiguous genitalia [Malan et al., 2006]. Although we were unable to verify karyotypes from other tissues including reproductive organs and histological evaluation, we could not find the third or fourth allele for each autosome pair or the second or third allele for the $\mathrm{X}$ chromosome.

There are several plausible hypotheses for the formation of the isodisomic $\mathrm{X}$ zygote. Theoretically, 4 conceptuses could be produced during gametogenesis: 46,XY, 46,X,der(Y), 47,XXY, and 47,XX,der(Y) (fig. 4A). First, isodisomic $\mathrm{X}$ chromosomes might be generated from the $46, \mathrm{X}, \operatorname{der}(\mathrm{Y})$ zygote during very early mitotic division (fig. 4D) although formation of the der(Y) could occur at paternal meiosis I $(46, \mathrm{X}, \operatorname{der}(\mathrm{Y})$, fig. $4 \mathrm{~A})$ or at postzygotic division (fig. 4D). 45, $\mathrm{X}$ is consequently formed, resulting in 46,XX lineages due to monosomy duplication (fig. 4D). Second, isodisomic $\mathrm{X}$ chromosomes from zygotes of 47,XXY and 47,XX,der(Y) might have arisen during maternal meiosis (fig. 4A, B), and generation of $\operatorname{der}(\mathrm{Y})$ might occur at paternal meiosis I or at early embryogenesis as described above. 47,XX,der(Y) might then produce 46,XX branching off 45 , X due to the postzygotic anaphase lag and 46,X,der(Y) (fig. 4C).

There are few reported cases of UPD X chromosome. The maternally derived UPD X chromosome is thought to be an unlikely origin of the imprinting effect in normal females [Avivi et al., 1992]. Schinzel et al. [1993] reported a case of $45, \mathrm{X} / 46, \mathrm{XX}$ involving short stature and a few other stigmata of Turner syndrome possibly due to the effects of a 45,X lineage. A case of maternally isodisomic $\mathrm{XX}$ was reported in a female patient with Duchenne mus-

Maternal Uniparental Isodisomic X

Chromosome Mosaicism cular dystrophy who did not show any effects of imprinted genes [Quan et al., 1997]. A paternal UPD XY chromosome was also identified in a case of father-son transmission of hemophilia A [Vidaud et al., 1989].

There are some limitations in our study. First, there are the possibilities of less expressed hidden alleles for STR markers of the X chromosome showing maternal and paternal alleles in size. Second, the UPD X chromosome should be confirmed for uniparental heterodisomy generation at maternal meiosis I or for uniparental isodisomy generation at maternal meiosis II, for example by using the single nucleotide polymorphism (SNP) array technique. However, the most plausible mechanism for this patient's karyotype is the production of the derivative $\mathrm{Y}$ chromosome in paternal meiosis I or in early embryogenesis and the subsequent generation of a 45, $\mathrm{X}$ lineage due to failure of X-Y bivalent formation resulting in $46, \mathrm{XX}$ as a consequence of monosomy duplication or mitotic nondisjunction during mitosis.

Although the patient showed azoospermia due to complete deletion of $\mathrm{AZFb}$ and $\mathrm{AZF}$ c and a high proportion of mosaicism of 46,XX and 45,X, we assumed that expression of the duplicated $S R Y$ gene might affect male urological development, and the 46,XX line would have less effect because it was generated during late postzygotic divisions after sex determination. Although isodisomy of the 46,XX lineage in the present case would have some of the same effects as a $45, \mathrm{X}$ lineage, it would not have the significant effects that result in the development of Turner syndrome. Therefore, the high degree of 46,XX and $45, \mathrm{X}$ mosaicism should not be a predictive indicator for clinical symptoms [Roovere et al., 2007].

In addition, we suggest that the $45, \mathrm{X}$ lineage, observed in common patterns of sex chromosome mosaicism with 46,XX and/or an aberrant Y chromosome, should elucidate mosaicism, chimerism, and UPD. There might be a correlation between clinical manifestations and the 45,X ratio and/or a possibility of $\mathrm{X}$ chromosome isodisomy of 46,XX [Patsalis et al., 2005]. A recent study reported the mechanisms of mosaicism, chimerism, and UPD using a genome-wide SNP array [Conlin et al., 2010]. However, it is difficult to investigate chimerism and UPD in all cases with mosaicism. We propose allele fragment analysis to improve the reliability of routine clinical cytogenetic diagnosis. In addition, asymmetrically rearranged $\mathrm{Y}$ chromosomes such as the present derivative Y chromosome could be misdiagnosed because of their similar shape to the diminished Yq12 region.

In conclusion, to the best of our knowledge this is the first attempt to verify isodisomic X chromosomes of 46, XX 
and 45,X mosaicism in an infertile individual carrying a $\mathrm{Y}$ chromosome abnormality. Routine cytogenetic and molecular techniques helped to determine the origin of the mosaicism and rearranged chromosomes which might be useful information for reducing misdiagnosis, predicting the patient's clinical features during genetic counseling and planning artificial reproductive technologies.

\section{Acknowledgements}

We thank Shin, ES, PhD, for the additional allelic analysis (Genome Research Center, NEODIN Medical Institute).

\section{References}

-Antonelli A, Marcucci L, Elli R, Tanzi N, Paoli D, et al: Semen quality in men with Y chromosome aberrations. Int J Androl 34:453-460 (2011).

Avivi L, Korenstein A, Braier-Goldstein O, Goldman B, Ravia Y: Uniparental disomy of sex chromosomes in man. Hum Genet 51:A11 (1992).

-Bertini V, Canale D, Bicocchi MP, Simi P, Valetto A: Mosaic ring Y chromosome in two normal healthy men with azoospermia. Fertil Steril 84:1744 (2005).

Conlin LK, Thiel BD, Bonnemann CG, Medne L, Ernst LM, et al: Mechanisms of mosaicism, chimerism and uniparental disomy identified by single nucleotide polymorphism array analysis. Hum Mol Genet 19:1263-1275 (2010).

Cui YX, Shi YC, Liu Q, Xia XY, Lu HY, et al: A case of agonadism associated with Y-chromosome rearrangement: cytogenetic and molecular studies. J Androl 30:650-654 (2009).

Engel E: A fascination with chromosome rescue in uniparental disomy: mendelian recessive outlaws and imprinting copyrights infringements. Eur J Hum Genet 14:1158-1169 (2006).

Foresta C, Moro E, Ferlin A: Y chromosome microdeletions and alterations of spermatogenesis. Endocr Rev 22:226-239 (2001).

-Hsu LY: Phenotype/karyotype correlations of Y chromosome aneuploidy with emphasis on structural aberrations in postnatally diagnosed cases. Am J Med Genet 53:108-140 (1994).

-Hsu LY, Perlis TE: United States survey on chromosome mosaicism and pseudomosaicism in prenatal diagnosis. Prenat Diagn 4:97-130 (1984).

Lange J, Skaletsky H, van Daalen SK, Embry SL, Korver CM, et al: Isodicentric Y chromosomes and sex disorders as byproducts of homologous recombination that maintains palindromes. Cell 138:855-869 (2009).

- Lin YH, Chuang L, Lin YM, Lin YH, Teng YN, Kuo PL: Isochromosome of Yp in a man with Sertoli-cell-only syndrome. Fertil Steril 83: 764-766 (2005).
Malan V, Vekemans M, Turleau C: Chimera and other fertilization errors. Clin Genet 70:363373 (2006).

Mancini A, Zollino M, Leone E, Grande G, Festa $\mathrm{R}$, et al: A case of 45,X male: genetic reevaluation and hormonal and metabolic follow-up in adult age. Fertil Steril 90:2011.e17-21 (2008).

Oliveira RM, Verreschi IT, Lipay MV, Eça LP, Guedes AD, Bianco B: Y chromosome in Turner syndrome: review of the literature. Sao Paulo Med J 127:373-378 (2009).

Patsalis PC, Skordis N, Sismani C, Kousoulidou L, Koumbaris G, et al: Identification of high frequency of $\mathrm{Y}$ chromosome deletions in patients with sex chromosome mosaicism and correlation with the clinical phenotype and Ychromosome instability. Am J Med Genet A 135:145-149 (2005).

Peschka B, Leygraaf J, Van der Ven K, Montag M, Schartmann B, et al: Type and frequency of chromosome aberrations in 781 couples undergoing intracytoplasmic sperm injection. Hum Reprod 14:2257-2263 (1999).

Roovere T, Peters M, Horelli-Kuitunen N, Mölter-Väär T, Punab M, et al: Cytogenetic and molecular characterization of the derivative $\mathrm{Y}$ chromosome: a case study of an azoospermic patient. Clin Genet 72:460-463 (2007).

Quan F, Janas J, Toth-Fejel S, Johnson DB, Wolford JK, Popovich BW: Uniparental disomy of the entire $\mathrm{X}$ chromosome in a female with Duchenne muscular dystrophy. Am J Hum Genet 60:160-165 (1997).

Schinzel AA, Robinson WP, Binkert F, Torresani T, Werder EA: Exclusively paternal X chromosomes in a girl with short stature. Hum Genet 92:175-178 (1993).

Shi YC, Cui YX, Zhou YC, Wei L, Jiang HT, et al: A rare $\mathrm{Y}$ chromosome constitutional rearrangement: a partial AZFb deletion and duplication within chromosome Yp in an infertile man with severe oligoasthenoteratozoospermia. Int J Androl 34:461-469 (2011).
Shinawi M, Cain MP, Vanderbrink BA, Grignon DJ, Mensing D, et al: Mixed gonadal dysgenesis in a child with isodicentric $\mathrm{Y}$ chromosome: does the relative proportion of the 45,X line really matter? Am J Med Genet Part A 152A:1832-1837 (2010).

-Siffroi JP, Le Bourhis C, Krausz C, Barbaux S, Quintana-Murci L, et al: Sex chromosome mosaicism in males carrying $\mathrm{Y}$ chromosome long arm deletions. Hum Reprod 15:25592562 (2000).

Tuck-Muller CM, Chen H, Martinez JE, Shen CC, Li S, Kusyk C, et al: Isodicentric Y chromosome: cytogenetic, molecular and clinical studies and review of the literature. Hum Genet 96:119-129 (1995).

Vidaud D, Vidaud M, Plassa F, Gazengel C, Noel $\mathrm{B}$, et al: Father to son transmission of hemophilia A due to uniparental disomy. Am J Hum Genet 59:A226 (abstract) (1989).

Vogt PH: Human chromosome deletion in Yq11. AZF candidate genes and male infertility: history and update. Mol Hum Reprod 4:739-744 (1998).

Vogt PH: Genomic heterogeneity and instability of the AZF locus on the human chromosome. Mol Cell Endocrinol 224:1-9 (2004).

Vogt PH, Edelmann A, Kirsch S, Henegariu O, Hirschmann P, et al: Human Y chromosome azoospermia factor (AZF) mapped to different subregions in Yq11. Hum Mol Genet 5: 933-943 (1996).

Vollrath D, Foote S, Hilton A, Brown LG, BeerRomero P, et al: The human Y chromosome: a 43-interval map based on naturally occurring deletions. Science 258:52-59 (1992)

Wheeler M, Peakman D, Robinson A, Henry G: 45,X/46,XY mosaicism: contrast of prenatal and postnatal diagnosis. Am J Med Genet 29: 565-571 (1988).

-Winberg J, Gustavsson P, Lagerstedt-Robinson K, Blennow E, Lundin J, et al: Chimerism resulting from parthenogenetic activation and dispermic fertilization. Am J Med Genet A 152A:2277-2286 (2010).

-Yamazawa K, Nakabayashi K, Kagami M, Sato T, Saitoh S, et al: Parthenogenetic chimerism/ mosaicism with a Silver-Russell syndromelike phenotype. J Med Genet 47:782-785 (2010). 